\title{
Social Structure of Pods' Correlation to Frequency of Repetitive Pacing in Captive Beluga Whales
}

\author{
Gianna Perugini ${ }^{1}$ and Jamela Orrego" \\ 1J.W. Mitchell High School, Trinity, FL, USA \\ \#Advisor
}

\section{$\underline{\text { ABSTRACT }}$}

Beluga whales in captivity currently show signs of mental distress through stereotypical behaviors such as repetitive pacing. It is currently well established that the social structure of beluga whale pods can alter beluga whale social behavior. This study aims to determine how differing social structures of beluga whale pods correlate to the frequency of repetitive pacing. In this context repetitive pacing is when a beluga whale paces three or more laps in the same pattern and direction. To test the hypothesis that beluga whales in larger more diverse pods will repetitively pace less than beluga whales in smaller more uniform pods, a behavioral observation was conducted at Seaworld Orlando and Georgia Aquarium. Over 20 observation periods, the amount of times repetitively paced, amount of laps while repetitively pacing, and the amount of laps repetitively paced per hour were all noted. The results supported the hypothesis, correlating the more diverse pod to less frequent repetitive pacing. These results suggest that pod social structure can play a role in captive beluga whales' mental wellbeing. On this basis, during future transfers, more diverse pods should be put together to try to limit the amount of repetitive pacing and improve the mental wellbeing of captive beluga whales.

\section{Introduction}

Currently there are over three hundred beluga whales in captivity worldwide, with thirty-three of which living in the United States (National Inventory of Marine Mammals). Under the Marine Mammal Protection Act, it is legal to hold cetaceans (dolphins, whales, and porpoises) on public display without a permit throughout the United States, in addition it is legal to import them from the wild (NOAA). However, throughout the country, the mental wellbeing of captive cetaceans has been of growing concern due to exposure of their captive lifestyles. This was amplified by documentaries such as Blackfish and The Cove exposing the horrors and flaws within the marine park industry. The viewing of such films motivated the general public to be concerned about the mental health of captive cetaceans. In an effort to make change many people began to stop going to parks that hold captive cetaceans, Seaworld's profits dropped $84 \%$ following the publication of Blackfish (TIME). In response to the negative stigma in regard to captivity and in an effort to raise attendance rates back up, Seaworld announced a breeding ban, in which they vowed to stop the breeding of orcas; however, other species like belugas and dolphins were excluded from this ban (Seaworld). This ban was simply to please the public, therefore left out any animals that the documentaries and the public did not focus on, one of those being beluga whales.

Despite their exclusion in breeding bans and debates, beluga whales have shown signs of mental distress from being in captivity, one of the most prominent being stereotypical behaviors. These behaviors are repetitive and unnatural, some of them such as jaw popping (widely opening mouth quickly) and head bashing (banging head into walls of tank) can be damaging to their physical wellbeing. Other stereotypical behaviors, like repetitive pacing and logging (floating at the surface of water), are indicative of poor mental wellbeing and boredom. A growing understanding of these behaviors have led to movements advocating for the release of these whales sponsored by organizations such as The Dolphin Project, People for the Ethical Treatment of Animals, and Sea Shepherd to try to advocate 
for the release of these whales. These organizations are hopeful that releasing these whales will result in improved mental wellbeing from living in the wild, or even sanctuaries.

On the other hand, a majority of the beluga whales currently captive in the United States were born into captivity, and would not know how to survive in the wild (National Inventory of Marine Mammals). Even if these whales were to be placed into a sea pen or sanctuary, where they would still be under the care of humans, the move could make their physical health deteriorate. Since these whales have spent the majority of their lives in captivity, their immune systems are not built to be able to fight off pathogens and toxins that are encompassed by the ocean, making them more susceptible to disease and infection (NOAA). Since the release of the whales is not a viable solution for improving their mental wellbeing, it is important to determine possible ways that could improve the emotional state of the whales without sacrificing their physical health. A possible solution could be restructuring captive pods to establish a more socially stimulating environment for the whales that better models how they would live in the wild.

\section{Literature Review}

In 2018, animal welfare specialists, Isabella L. Clegg and Fabienne Delfour analyzed the behaviors of Atlantic bottlenose dolphins to determine that certain behaviors and mannerisms can be applied to measuring their wellbeing. Specifically, they concluded how the presence of behaviors known as "stereotypical behaviors" (unnatural, repetitive behaviors) can be indicative of poor mental welfare and boredom of marine mammals (Clegg). This analysis of behavior can make behavior an essential factor in welfare assessments of marine mammals. Furthermore, zoologist at University of Oxford, Joseph Garner was performing research and noticed that his observations lacked reliability and replicability as behavior of animals changes based on if they are in a wild or captive environment. This led to him researching how the behavior of animals changed based on their environment. His observations led to the conclusion that when an animal is in a captive environment they will begin to perform "stereotypical behaviors" (JP Garner). To further the points made by Clegg and Garner, research by biologists M. Elsbeth McPhee and Kathy Carlstead explained how there is correlation between the amount of boredom a mammal has and the amount of stereotypical behaviors they show. When the animals were in a situation that would increase their boredom, the amount of stereotypical behavior they exhibited decreased (McPhee). Through this data, it is emphasized that behaviors of mammals are greatly influenced by their environment such as tank size as well as their level of boredom. Therefore, this research concluded that behavior is a strong measure of a mammal's mental wellbeing, making the frequency of certain behaviors a plausible way to measure if a cetacean is pleased with their current living situation or needs a change to help boost their wellbeing.

As a cetacean species, beluga whales also present certain stereotypical behaviors. A common behavior among captive beluga whales is behavioral laterality (preference to one side or direction). Lori Marino and Jeniffer Stowe of Emory University's Department of Biology, observed this by studying two captive male beluga whales who maintained a clockwise swimming pattern in which they did not swim in a different direction either together or apart (Marino). Through behavioral laterality, the stereotypical behavior of repetitive pacing in beluga whales is established. This creates an unnatural set of behaviors that can be harmful to both the physical and mental health of the whales.

Important to note as well is that much of beluga's social interaction and communications is done vocally. Due to their audible communication methods they have been nicknamed 'Canary of the Sea' as their frequent vocalizations in the wild are often heard from shore. Two Bioacousticians, Manuel Castellote and Fulvio Fossa, observed that the vocalizations of these whales decrease in frequency when in captivity and can be further indicative of mental wellbeing (Castellote). According to Greg O' Corry-Crowe of Harbor Branch Oceanographic Institute at Florida Atlantic University wild beluga whales tend to travel long distances throughout the day and are extremely social. They interact with each other through playful, aggressive, and sexual behavior in the wild (O' Corry-Crowe), and while these behaviors are still present in captivity they have been unnaturally altered and changed due to the artificial environment in which they live. Thus, whales may begin to mimic how they would travel in the ocean. However, when a 
whale is pacing to get in the exercise they are lacking this will not be done repeatedly in the same pattern, the pattern will change per lap.

Beluga whales' social behavior has led them to living in pods in the wild, and to best accommodate to their social nature all facilities in the United States are home to more than one beluga whale. However, the number of whales and pod structure does vary per facility (National Inventory of Marine Mammals). In the wild, beluga whales tend to swim with their relatives, developing a system of kinship. While multiple families tend to travel together in the same pod, beluga whales of the same family line tend to spend more time together (O' Correy-Crowe). Similarly, in captivity, male beluga whales are more likely to spend time with another male beluga whale instead of a female beluga whale. However females tend to show no preference in the sex of their pod mates (Mazikowski). It is important to note that each individual whale in a pod is different and has their own personality, this difference and variety in the whales personalities can make them behave differently and prefer different social structures than the typical whale (Hill). In the wild the whales are able to freely pick and choose their pod mates, meanwhile in captivity their pod mates are chosen for them, meaning if they do not like their pod structure they have no way of changing or escaping it.

The behavior of beluga whales can change based around their environment and pod structure. Captive toothed whale species, bottlenose dolphins and finless porpoises, in China have been recorded to increase in repetitive pacing (swimming continuously in the same pattern) during periods of social isolation and separation (Serres A.). Through the establishment that social separation can cause increases in stereotypical behaviors, it furthers that stereotypical behaviors are indicative of the mental wellbeing of whales, and can potentially change in frequency due to the social structure they are in. During research on a beluga whale pod at Seaworld San Antonio, beluga whales were observed as they rotated among different social structures throughout the day. It was shown that the entire pod would be more active if there was a juvenile in the pod. Additionally, when the especially lethargic adults were around younger and energetic whales they would become more active in comparison to how they acted in a pod of all adult whales (Hill). Knowledge of the change of behavior based around other members of the pod began to raise questions about how social structure can change the behavior of individuals in the pod. Research done by Danielle Halteman and Wendy Ryan showed that when beluga whales at Mystic Aquarium are in a larger pod they tend to more frequently participate in a larger variety of social behaviors than whales in smaller pods. The pod originally consisted of two females and one male, however, when another male was introduced the social behavior of the pod increased, especially between the two males (Halteman). This, evidently, shows that beluga whales will alter their behavior if the social structure of their pod is altered, even slightly.

While it has been established that whales' behavior can change based on their pod mates, especially in captive settings, it has never been addressed whether or not pod social structure can reduce the frequency of stereotypical behaviors such as repetitive pacing, therefore indicating which pod structure would positively impact the mental wellbeing of whales. This led to the development of the research question: does the differing social structures of captive pods of Delphinapterus leucas correlate to the frequency of repetitive pacing of individuals within the pods? This will be researched through a behavioral observation and a correlation study, observing two different beluga whale pods across two different facilities in North America.

\section{Methods}

The most effective way to research the effect of differing social structures on the frequency of repetitive pacing in beluga whales was through a behavioral observation and correlation study. A behavioral observation was the best option to collect the data as it allowed for a wide variety of data (amount of times repetitively paced, laps while repetitively pacing, total laps repetitively paced in an hour) that was taken during times of little interference to get the most accurate results. If a content analysis was used the videos would have a limited view and could be taken during a time of a lot of enrichment (toys in pool, stimulation at the glass) making it hard to take into account the limitations. In addition, a content analysis would have varying video lengths making it hard to determine how frequent repetitive 
pacing was occurring. A correlation study of analysis was then utilized to determine the meaning behind the observations and fully answer the question.

The behavioral observation occurred both in person and remotely at two different facilities: Seaworld Orlando and Georgia Aquarium. Each of the facilities offered a different social structure. Seaworld Orlando had the smallest and least diverse pod, housing two thirteen year old male beluga whales. Contrastingly, Georgia Aquarium had the largest and most diverse pod, housing four females and two males with ages ranging from 32 to less than a year old. Each of the whales at each facility have spent all or more than ninety percent of their life in captivity, so they have little to no understanding of life in the wild. These facilities also had different tank sizes, Georgia Aquarium's tank is about 800,000 US gallons averaging about 133,000 US gallons per whale while Seaworld Orlando's tank is about 591,971 US gallons averaging about 295,000 US gallons per whale. While the tank size at Seaworld Orlando is smaller, it is actually larger in proportion to the number of whales making the differences balance out.

Beluga whales all have defining characteristics that help to tell them apart, to accurately observe each individual whale it was important to know how to identify each of the whales being observed to prevent confusion between which whale was repetitively pacing. The whales were identified via certain features that were unique to them, and how they looked in comparison to their pod mates (refer to Table 1 for reference on the identification of each of the whales observed).

Table 1. Depicts the unique characteristics of each whale that were used to identify the whales during the research period.

\begin{tabular}{|c|c|}
\hline Seaworld Orlando Beluga Whales & Identifying Characteristics \\
\hline Grayson & $\begin{array}{l}\text { Male, } 13 \text { years old. } \\
\text { White coloration, grey speckles on top of melon (head). }\end{array}$ \\
\hline Oliver & $\begin{array}{l}\text { Male, } 13 \text { years old. } \\
\text { Light grey coloration, white birthmark on right melon } \\
\text { line (where melon connects to mouth), pectoral flippers } \\
\text { curl upwards. }\end{array}$ \\
\hline Georgia Aquarium Beluga Whales & Identifying Characteristics \\
\hline Imaq & $\begin{array}{l}\text { Male, } 33 \text { years old. } \\
\text { Tail flukes appear wavy, very large melon (head), the } \\
\text { largest member of the pod. }\end{array}$ \\
\hline Maple & $\begin{array}{l}\text { Female, } 15 \text { years old. } \\
\text { Distinct white coloration, notches on ends of pectoral } \\
\text { flippers, and a notch on the left side of her mouth. }\end{array}$ \\
\hline Nunavik & $\begin{array}{l}\text { Male, } 11 \text { years old. } \\
\text { Melon line (where head connects to mouth) is not con- } \\
\text { tinuous, it is split into three parts, the first half of his } \\
\text { body has wrinkles. }\end{array}$ \\
\hline Qinu & $\begin{array}{l}\text { Female, } 12 \text { years old. } \\
\text { Grey tail flukes and pectoral flippers, small indentation } \\
\text { in her mouth. }\end{array}$ \\
\hline
\end{tabular}




\begin{tabular}{|l|l|}
\hline Shila & $\begin{array}{l}\text { Female, 7 months old. } \\
\text { Very small and grey, only baby in the pod. }\end{array}$ \\
\hline Whisper & $\begin{array}{l}\text { Female, 21 years old. } \\
\text { Grey coloration, wrinkles and marks throughout her } \\
\text { skin. }\end{array}$ \\
\hline
\end{tabular}

Once the identifying characteristics were determined the behavioral observation began. The pods were observed for a total of fifteen hours each in one hour intervals in the time frame of 12:00 P.M. - 8:00 P.M. This time period was chosen as earlier in the day there were a lot of training and enrichment sessions, which would make it difficult to get an hour of observations in without interruption. In addition, during the later time period the facilities tend to be less crowded, providing less distraction to the whales natural behavior. Beluga whale behavior can change throughout the day, so it was also important to have a wide time period to allow for that variation as well. To eliminate any non-social factors that could alter their behavior, all observations occurred when there was little/no enrichment in the tank and no training sessions occurring for the beluga whales at that time. Each pod was observed individually, so no two pods were observed at the exact same time.

The Seaworld Orlando whales were observed in the underwater viewing center, however, no noise or movements were made by the observer to alter their behavior. Georgia Aquarium had a live stream of their beluga tank running on their website, therefore, their pod was observed over live cam. The use of live streams was chosen to limit the amount of travel for the researcher, so since the live streams provided similar views to what the observer would see in person, it cut costs and time of transportation to and from different states. The use of live cams also eliminated any possible distraction of the whales made by the observer's presence.

During the observation period a tally was marked for each time a whale made a lap, a consecutive lap in the same pattern was marked by another tally. If the pattern was broken a ' $X$ ' was marked. Once the whale began to make laps again a new set of tallies began after the ' $\mathrm{X}$ '. This was continued for every whale in the pod throughout each hour observation period. The use of this line and ' $\mathrm{X}$ ' system was the most accurate way of keeping track of the data, especially while observing the larger pods. By marking tallies the observer could keep track of how many laps in each session of repetitive pacing, and how many times the whale repetitively paced.

The data was analyzed after each observation period for the frequency that each individual whale repetitively paced and the average amount of laps they paced while repetitively pacing was calculated. Then the average for the amount of times repetitively paced and the number of laps will be averaged for the pod. After all the observation periods for a pod, there were 20 different averages for both the amount of times and the number of laps paced. These were then averaged to create two averages, representative of all the observation periods. This was done for each of the pods. To help eliminate any discrepancies caused by differences in the amount of laps per session of repetitive pacing, these two averages were also multiplied together to determine the average total amount of laps repetitively paced per hour observation period. Then a correlation coefficient was calculated to determine the level of correlation between pod structure and amount of times paced as well as between pod structure and amount of laps while pacing.

\section{Results}

In order to determine if beluga whale pod social structure correlates with the amount of repetitive pacing done by beluga whales, observations were conducted. The quantitative data was compiled after 20 observation periods: 10 at Seaworld Orlando (the least diverse pod), and 10 at Georgia Aquarium (the most diverse pod).

Through comparison of the data between Seaworld Orlando and Georgia Aquarium it was established that the beluga whales at Seaworld Orlando repetitively paced more than the beluga whales at Georgia Aquarium. First, the average amount of times repetitively paced per observation period at Seaworld Orlando was 6.65 while at Georgia 
Aquarium it was 1.27. Though this shows that beluga whales at Seaworld Orlando may have had more repetitive pacing sessions, it was critical to consider that these repetitive pacing sessions consisted of different amounts of laps, therefore the average amount of laps per session of repetitive pacing was calculated. The beluga whales at Seaworld Orlando tended to average 3.72 laps while repetitive pacing, meanwhile the Georgia Aquarium whales averaged about 3. 23 laps, the closeness in these averages eliminated possible skew of whales repetitively pacing less times but more laps. This indicates that Seaworld Orlando pod had repetitively paced more frequently than the Georgia Aquarium pod even with the consideration of number of laps while repetitive pacing.

\section{Average Number of Times Whales Repetitively Paced Per Observation Period}

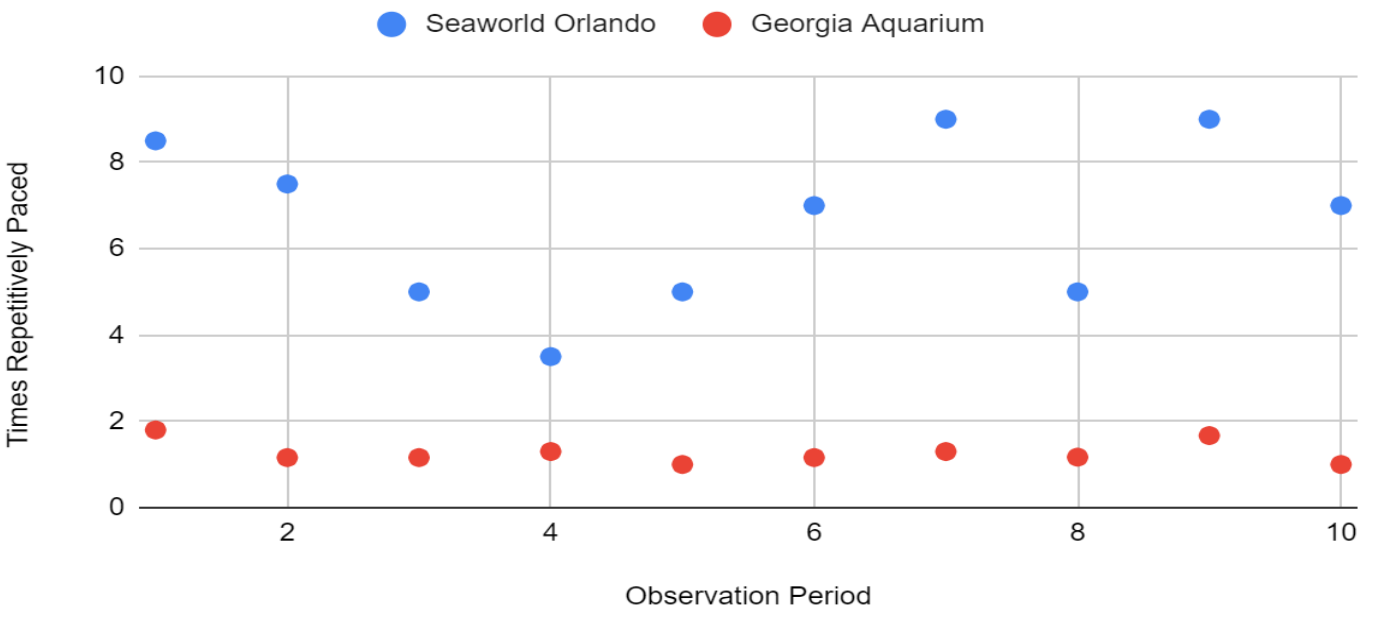

Figure 1. Shows the amount of times repetitively paced per observation session.

To get a more accurate representation of the difference in the amount of repetitive pacing per each pod, the number of times repetitive paced and the number of laps while repetitive pacing were multiplied together for each faculty observed. The product is representative of the number of laps paced per individual during an hour observation period. The beluga whales at Seaworld Orlando, the least diverse pod, had an average number of 25.01 laps repetitively paced per individual during an hour observation period. Conversely, the beluga whales at Georgia Aquarium, the most diverse pod, had an average number of 4.01 laps repetitively paced per individual during an hour observation period. See Table 2 to see a breakdown by each observation period.

Table 2. and Figure 2. Show the average number of laps repetitively paced by each individual per observation period for each facility.

\begin{tabular}{|l|l|l|}
\hline Observation Period & Seaworld Orlando & Georgia Aquarium \\
\hline 1 & 34 & 5.76 \\
\hline 2 & 29.63 & 3.57 \\
\hline 3 & 17.13 & 4.87 \\
\hline 4 & 12.5 & 3.9 \\
\hline 5 & 17.3 & 3.25 \\
\hline 6 & 24.99 & 4.06 \\
\hline 7 & 34.79 & 3.9 \\
\hline 8 & 17.5 & 3.5 \\
\hline
\end{tabular}




\begin{tabular}{|l|l|l|}
\hline 9 & 33.98 & 5.18 \\
\hline 10 & 28.25 & 3 \\
\hline
\end{tabular}

\section{Average Number of Laps Repetitively Paced by each Whale per Observation Period \\ Seaworld Orlando \\ Georgia Aquarium}

40

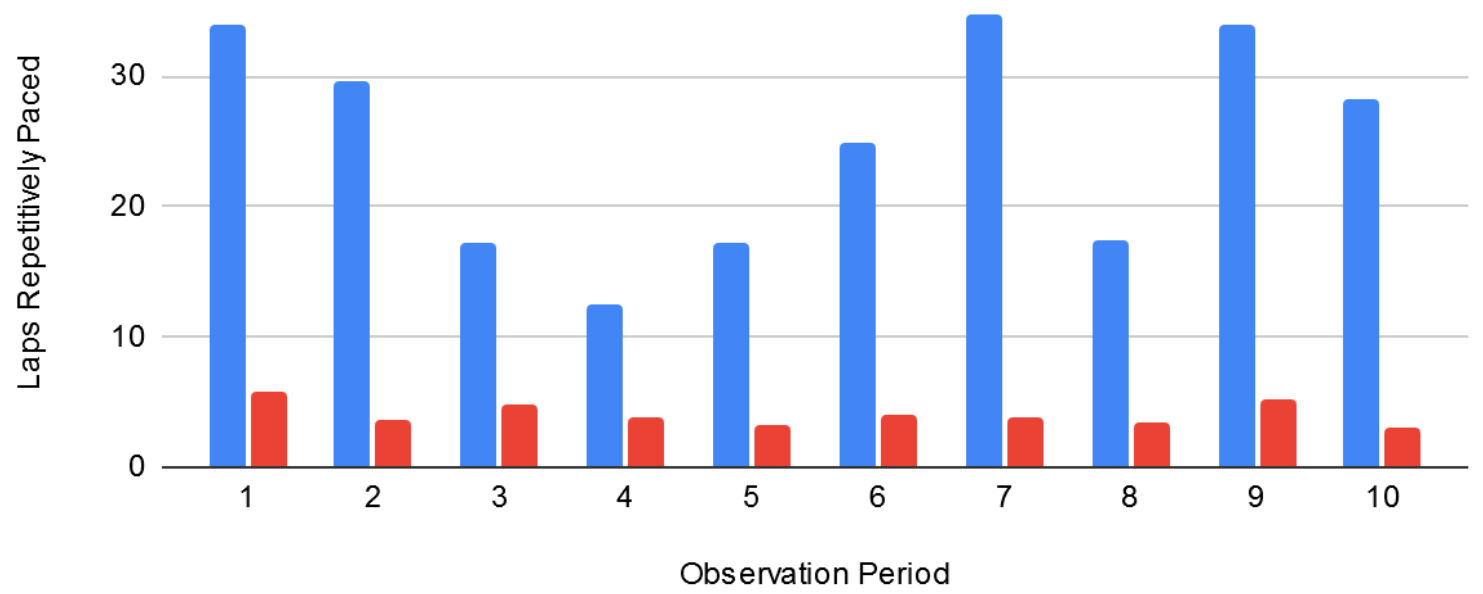

As seen above in Table 2 and Figure 3, despite varying amounts of repetitive pacing per observation period, there was consistent data showing the beluga whales at Seaworld Orlando repetitively pacing more than the beluga whales at Georgia Aquarium. To further establish this a correlation coefficient was calculated, representative of the average amount of laps paced during the observation period. The correlation coefficient for the average amount of laps paced between the Seaworld Orlando and Georgia Aquarium whales was -0.88 indicating a strong negative correlation, meaning that the more diverse pod repetitively paced significantly less than the less diverse pod. However, to further outline the validity and significance of these results, a statistical analysis was conducted to determine if there were any outliers in the data set and analyze each section in the data set to check the consistency of the correlation.

Table 3. and Figure 3. statistical analysis including the minimum (min), first quartile (Q1), second quartile (Q2), third quartile $(\mathrm{Q} 3)$, and the maximum.

\begin{tabular}{|l|l|l|l|l|l|}
\hline & Min & Q1 & Q2 & Q3 & Max \\
\hline $\begin{array}{l}\text { Seaworld Or- } \\
\text { lando }\end{array}$ & 12.5 & 17.3 & 26.62 & 33.98 & 34.79 \\
\hline $\begin{array}{l}\text { Georgia Aquar- } \\
\text { ium }\end{array}$ & 3 & 3.5 & 3.9 & 4.87 & 5.76 \\
\hline
\end{tabular}



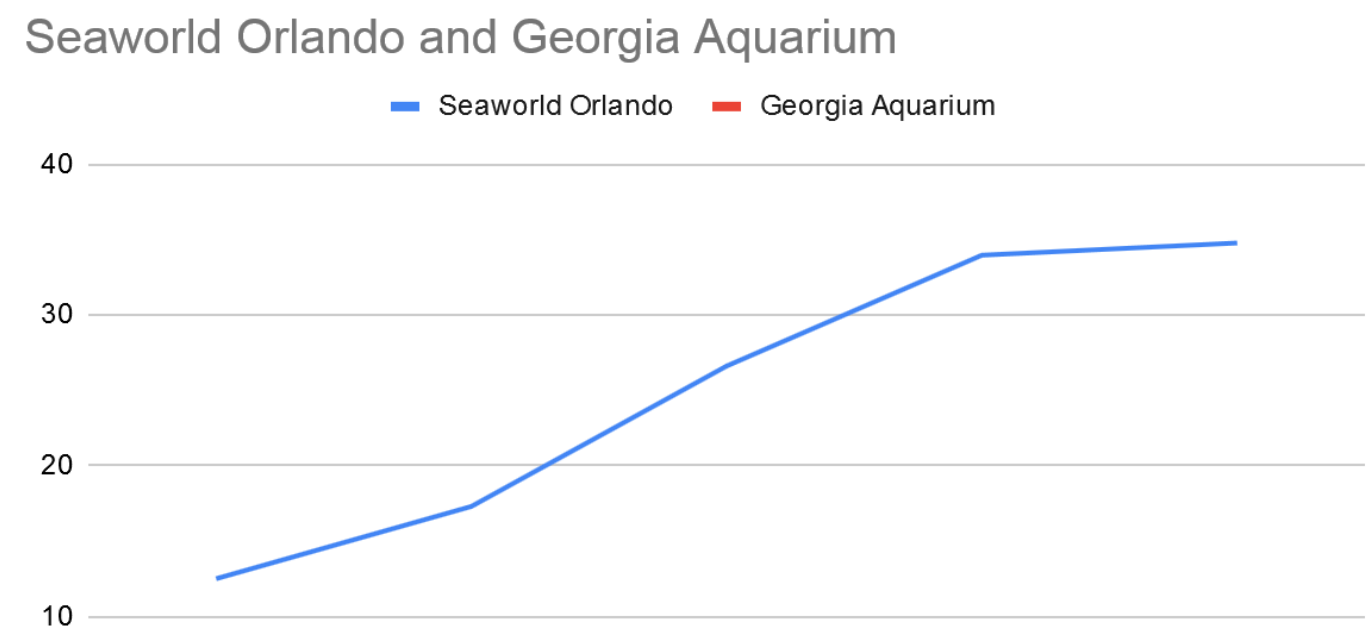

$$
0
$$

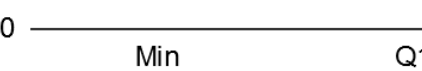

Q2

Q3

Max

The data consisted of no outliers, indicating all the data fell within the range. In addition the minimum, first quartile, second quartile, third quartile, and maximum were all significantly higher for the Seaworld Orlando pod than the Georgia Aquarium pod. This indicates that the entirety of the data indicates this negative correlation, and the means were not manipulated by outliers, indicating there is a significant strong correlation between increased repetitive pacing and less diverse pod structures representative throughout the whole data set.

Between both the amount of times repetitive paced and the number of laps paced during an observation period the Seaworld Orlando pod repetitively paces significantly more than the Georgia Aquarium, however both paced about the same amount of laps while they were repetitively pacing. To show the breakdown comparison between Seaworld Orlando and Georgia Aquarium in regard to number of times repetitively paced, number of laps while repetitive pacing, and average number of laps repetitively paced per observation period a stepped area chart was created and is shown below in Figure 6.

Figure 4. shows the average number of times repetitively pacced, average number of laps while repetitively pacing and average number of laps repetitively paced during an observation period for comparison. 


\section{Repetitive Pacing at Seaworld Orlando vs Georgia Aquarium \\ Seaworld Orlando Georgia Aquarium \\ 30}

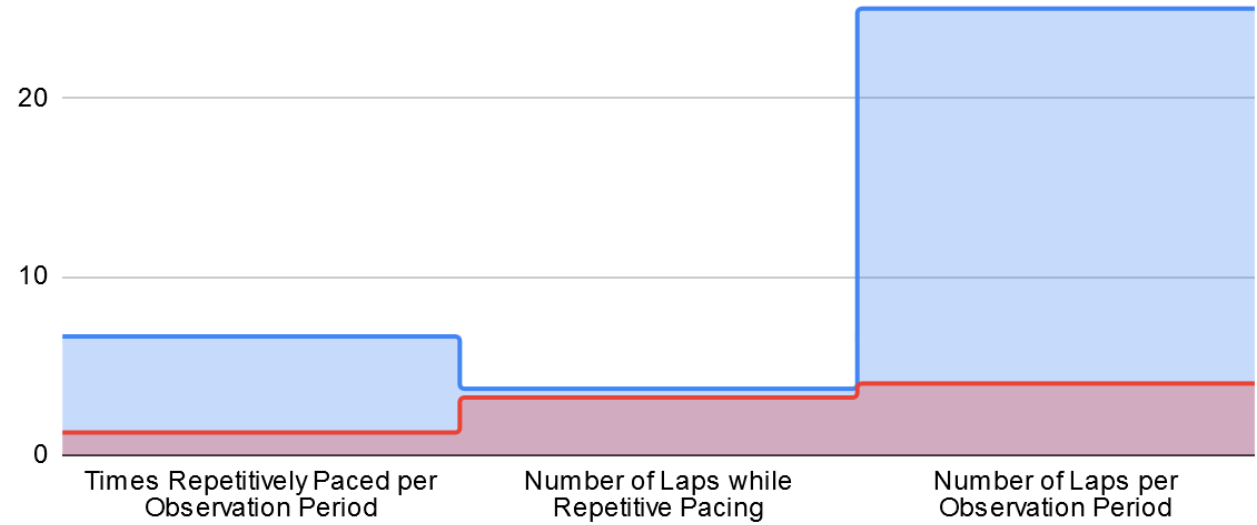

\section{Discussion}

The beluga whales at Seaworld Orlando in the least diverse pod repetitively paced more than the beluga whales in the most diverse pod at Georgia Aquarium over an hour long period. This was revealed through analysis of the average amount of times repetitively paced, number of laps while repetitively pacing, and most significantly through the average the number of laps paced per individual during each observation period. The correlation coefficient was calculated based on the average number of laps paced per individual and was - 0.88 , indicating a strong negative correlation. The analysis of these results indicates that social structure correlates to the amount of repetitive pacing done in the pod. In addition, these findings supported the hypothesis that the beluga whales in the most diverse pod would repetitively pace less than the beluga whales in the least diverse pod. This data aligns with the research done by Halteman, beluga behavior does change based on the size and diversity of their pod (Halteman), and aligns with Hill's research that adult beluga whales housed with younger beluga whales tend to become more active, both socially and physically (Hill).

This correlation is likely caused by the increased social stimulus of being in a larger, more diverse pod. In the wild beluga whales are very social animals and tend to swim in pods of 4-10 of varying ages and sexes (O'CorryCrowe). Therefore, the Georgia Aquarium pod would be the most natural to that of whales in the wild, consisting of 6 beluga whales, 3 male, 3 female, 5 adult, 1 baby. Meanwhile the Seaworld Orlando pod is significantly smaller than the typical wild beluga whale pod, showing that this would be more unnatural for them. It is important to try to promote as natural of a captive environment as possible to promote more natural behavior in the whales and limit stereotypical behaviors (Mcphee).

While repetitive pacing and social structure correlate with each other it is important to note potential limitations in the data, and correlation does not always equal causation. While repetitive pacing is a key, common, and prominent stereotypical behavior, there are other stereotypical behaviors that can be indicative of poor mental health and boredom in beluga whales. As mentioned in O' Cory Crow's research, every beluga whale has its own unique personality and preferences so it could be possible that other stereotypical behaviors such as logging (floating at the surface) are preferred by the beluga whales at Georgia Aquarium therefore causing them to repetitively pace less because they spend more time simply logging and less time swimming repetitively. 
Another key factor which could affect the data's accuracy is that Seaworld Orlando and Georgia Aquarium are not perfectly identical, they have differing amounts of training sessions a day, tank sizes, and amount of enrichment could all also impact the amount of repetitive pacing and the overall mental health of their beluga whales. As indicated in Clarks research, enrichment plays a key role in reducing the frequency of repetitive pacing in captive marine mammals (Clark). However, while the beluga whales at Georgia Aquarium may receive more enrichment than the beluga whales at Seaworld Orlando, all of the sessions occurred with little to no enrichment in the tank to help reduce this from being an underlying factor. In addition, the beluga whales at Seaworld Orlando have more training/interactive sessions, which could balance out their lack of enrichment as these sessions are usually considered entertaining and stimulating to them as shown in Mcphees' research that training sessions including natural behaviors helps maintain a whales mental health and reduce the frequency in stereotypical behaviors (Mcphee).

Despite these limitations, the strong negative correlation shows a significant relationship between pod structure and the frequency of repetitive pacing emphasized by previous research done by Halteman and Hill that showed that beluga whale behavior changes based off of social structure and now shows indication that stereotypical behaviors, such as repetitive pacing is affected by the social structure of captive pods.

\section{Future Directions}

Future research that should be done to further address the limitations is research looking at different types of stereotypical behaviors than repetitive pacing such as logging (floating at the surface), as during the observation periods it was noticed that much of the time not repetitively pacing was spent logging, so knowledge on if the correlation between pod structure and stereotypical behaviors is extended to include logging. Furthermore, while there were attempts to expand the observation group to include Mystic Aquarium, technical difficulties with livestreaming made there not be sufficient or accurate enough data to draw conclusions. Therefore, it would be beneficial to include more facilities such as Seaworld San Antonio, Seaworld San Diego, Mystic Aquarium, and Shedd Aquarium in future research to have a more accurate sample of facilities across North America. To eliminate confounding variables such as tank size, Seaworld San Antonio offers an opportunity to observe multiple different pod structures in the same pool under all the same conditions just different whales put together, as they have so many different pools with so many whales that are separated in sub pods for periods of the day.

\section{Conclusion}

While other research has established that beluga whales' social behavior will change based on the structure of the pod, this behavioral observation and correlation study data was the first indication that a pods' social structure can reduce the frequency of stereotypical behaviors such as repetitive pacing. With a strong correlation coefficient of - 0.88 between pod structure and repetitive pacing, the hypothesis that larger more diverse pods would have less repetitive pacing than smaller more uniform pods is supported. Considering that repetitive pacing is indicative of poor mental wellbeing and boredom in beluga whales it is important to address this correlation and try to promote a more socially stimulating environment for captive beluga whales. Therefore, during future beluga whale transfers, which tend to happen about every 4 years, more diverse pods should be put together to try to limit the amount of repetitive pacing and improve the mental wellbeing of captive beluga whales.

\section{Acknowledgments}

I would like to thank Jamela Orrego for her assistance and guidance throughout this process. I would also like to thank the aquariums for allowing me to observe their whales and conduct this research at their facilities. 


\section{References}

Castellote, M., \& Fossa, F. (2006). Measuring acoustic activity as a method to evaluate welfare in captive beluga whales (Delphinapterus leucas). Aquatic Mammals, 32(3), 325.

Clark, F. E. (2013). Marine mammal cognition and captive care: A proposal for cognitive enrichment in zoos and aquariums. Journal of Zoo and Aquarium Research, 1(1), 1-6.

Clegg, I. L. K., \& Delfour, F. (2018). Can We Assess Marine Mammal Welfare in Captivity and in the Wild? Considering the Example of Bottlenose Dolphins. Aquatic Mammals, 44(2), 181+

Garner, J. P. (2005). Stereotypies and other abnormal repetitive behaviors: potential impact on validity, reliability, and replicability of scientific outcomes. ILAR journal, 46(2), 106-117.

Halteman, D. M., \& Ryan, W. L. (2019). The Effect of Group Composition on the Social Behaviors of Beluga Whales (Delphinapterus leucas) in an Artificial Environment. Aquatic Mammals, 45(3), 303-310.

Hill, H., Guarino, S., Crandall, S., Lenhart, E., \& Dietrich, S. (2015). Young belugas diversify adult beluga (Delphinapterus leucas) behavior. Animal Behavior and Cognition, 2(3), 267-284.

Marino, L., \& Stowe, J. (1997). Lateralized behavior in a captive beluga whale (Delphinapterus leucas). Aquatic Mammals, 23, 101-104.

Mazikowski, L., Hill, H. M., \& Noonan, M. (2018). Young belugas (Delphinapterus leucas) exhibit sex-specific social affiliations. Aquatic Mammals, 44(5), 500-505

McPhee, M. E., \& Carlstead, K. (2010). The importance of maintaining natural behaviors in captive mammals. Wild mammals in captivity: Principles and techniques for zoo management, 2, 303-313.

O'Corry-Crowe, G., Suydam, R., Quakenbush, L., Smith, T. G., Lydersen, C., Kovacs, K. M., ... \& Ferrer, T. (2020). Group structure and kinship in beluga whale societies. Scientific reports, 10(1), 1-21.

Serres, A., Hao, Y., \& Wang, D. (n.d.). Swimming features in captive odontocetes: Indicative of animals' emotional state? Behavioral Processes, 170. https://doi.org/10.1016/j.beproc.2019.103998

Serres, A. (2019). The frequency of solitary behaviours in captive odontocetes is modulated by environmental and social factors. International Journal of Comparative Psychology, 3 